\title{
O DIÁLOGO E A PROBLEMATIZAÇÃO: APORTES PEDAGÓGICOS PARA A FORMAÇÃO CONTINUADA
}

\author{
Claudia Pereira de Pádua Sabia, Cláudio Roberto Brocanelli, Camila Godoy Paredes \\ Universidade Estadual Paulista - UNESP, Docente do Departamento de Administração e Supervisão Escolar, Marília, \\ SP. e-mail: fsabia@uol.com.br \\ PROEX
}

\section{RESUMO}

Inúmeras pesquisas são realizadas por estudiosos motivados a identificarem problemas que há muito afetam o sistema nacional de ensino. Dentro deste contexto, temas relacionados a metodologia, infraestrutura escolar, políticas públicas e igualdade de oportunidade são levantados constantemente; porém, é imprescindível investigar causas mais profundas que influenciam diretamente no ensino e na aprendizagem. Por meio da pesquisa-ação, identificamos lacunas deixadas pela formação inicial de professores e gestores educacionais e também a necessidade de contribuir com a formação desses profissionais, possibilitando uma prática mais significativa e qualificada. O objetivo central deste estudo é demonstrar a importância da formação continuada e apresentar a proposta "O Diálogo e a Problematização" com a rede pública estadual que está em andamento. A pesquisa está sendo desenvolvida em uma abordagem qualitativa. A metodologia utilizada é a pesquisa bibliográfica e coleta de dados. Como resultados, apontaremos possibilidades de transformação da prática pedagógica propiciada pela formação contínua dos educadores.

Palavras-chave: Formação Continuada, Formação de Professores, Educação, Pesquisa Ação, Profissionalização Docente.

\section{DIALOGUE AND THE PROBLEMATIZATION: PEDAGOGIC CONTRIBUTIONS FOR CONTINUING EDUCATION}

\begin{abstract}
Many searches are conducted by scholars motivated to identify issues that will most affect the national educational system. Within this context issues related to methodology, school infrastructure, public policy and equal opportunity are raised constantly, but it is essential investigate deeper causes that directly influence teaching and learning. Through action research identified gaps left by the initial training of teachers and educational managers and the need to contribute to their training, enabling a more meaningful and qualified practice. The central aim of this study is to demonstrate the importance of continuing education, and present the "Dialogue and the Problematization" proposal with public schools that is in progress. The research is being developed in a qualitative approach and data collection. The methodology used is the literature search. As results will point out possibilities of transformation of pedagogical practice fostered by continuous training of educators.

Keywords: Continuing Education, Teacher Training, Education, Action Research, Teachers Professionalization.
\end{abstract}




\section{INTRODUÇÃO}

Nas últimas décadas, temas relativos à formação e profissionalização docente tornaram-se cada vez mais emergentes em discussões sobre potenciais melhorias na educação, objetivando investigar fatos histórico-sociais que marcaram o início da atividade dos educadores e que até os dias atuais, influenciam negativamente no exercício da profissão, contribuindo com sua desvalorização e com o insucesso escolar.

Ao explorarmos um estudo realizado por TANURI (2000), constatamos que em seus primórdios era dispensável que professores e gestores escolares tivessem formação acadêmica adequada para o exercício de suas funções; em contra partida, requisitos como influência religiosa e política, boa conduta moral e habilidade para retórica eram relevantes para a contratação. Comumente, profissionais liberais e bacharéis de diversas áreas do conhecimento eram admitidos para ministrarem aulas em variados níveis de ensino (ROMANOWSKI, 2010 p. 79).

Conforme Nóvoa (1995, p.15), reiterando esta constatação:

[...] a função docente desenvolveu-se de forma subsidiária e não especializada, constituindo uma ocupação secundária de religiosos ou leigos das mais diversas origens. A gênese da profissão professor tem lugar no seio de algumas congregações religiosas, que se transformaram em verdadeiras congregações docentes. (NÒVOA, 1995, p.15)

Progressivamente, esse quadro foi se modificando na tentativa de dar um novo significado ao ensino como prática social. Era preciso que professores e gestores da educação se reinventassem e renovassem o ambiente escolar, ambicionando formar uma nova consciência educacional (TANURI, 2000).

Com as inúmeras reformas e a reestruturação curricular nas escolas houve uma grande necessidade de repensar a profissionalização docente, que passou a requerer "maior titulação, cursos de aperfeiçoamento e de pós-graduação, como também a participação em programas de formação continuada" (ROMANOWSKI, 2010 p.34).Essas medidas foram imprescindíveis na tentativa de preencher lacunas deixadas pela formação inicial e propiciar momentos de pesquisa, reflexão e partilha de conhecimento de forma que a formação docente fosse tornando-se mais consistente.

O objetivo principal desse estudo é analisarmos alguns aspectos históricos e conceituais da formação continuada, bem como apresentarmos o curso "O Diálogo e a Problematização: fundamentos para a educação continuada dos profissionais da 
educação de escolas públicas estaduais", de 180 horas que se encontra em andamento. Trata-se de um projeto de extensão e pesquisa sobre a formação continuada, orientado pelo diálogo e pela problematização, estruturado com a colaboração de gestores escolares e supervisores de ensino que relataram aos docentes da UNESP suas principais carências e dificuldades. Após encontros mensais durante o ano de 2012, foi realizado um diagnóstico coletivo das necessidades de formação destes profissionais e suas possibilidades de mudança na organização do trabalho na escola. Todas as atividades já desenvolvidas e as que estão sendo realizadas no momento, são fruto de reflexão conjunta e democrática, tornando o ambiente de formação um espaço de discussão e de busca de soluções condizentes com a realidade de cada escola, valorizando seus desafios, limites e possibilidades novas a partir de suas potencialidades.

\section{METODOLOGIA}

Em relação à metodologia utilizada, o estudo está sendo desenvolvido em uma abordagem qualitativa que apresenta, dentre outras, as características da historicidade e da contextualização com base no pressuposto de que os conhecimentos são históricos e determinados e necessitam ser abordados e identificados a partir de tempos e espaços que são construídos (MACHADO, 2007).

Esta investigação utiliza as pesquisas: bibliográfica, com a busca de livros e artigos relacionados à temática da formação continuada e a coleta de dados, utilizando como instrumento a entrevista semiestruturada. Os sujeitos participantes da pesquisa são os diretores, vice-diretores, coordenadores pedagógicos da rede estadual paulista que estão matriculados no curso "O Diálogo e a Problematização".

\section{DISCUSSÃO}

Para iniciarmos nossa discussão sobre formação de professores e gestores educacionais é imprescindível resgatar brevemente informações históricas, objetivando contribuir com nossa compreensão a respeito das políticas públicas, movimentos de reestruturação e deficiências que marcaram a constituição da carreira docente e que ainda nos dias atuais afetam a formação, a atuação e a profissionalização dos mesmos. (TANURI, 2000).

Conforme Tanuri (2000), a primeira escola normal brasileira surgiu a partir da aprovação da Lei no 10, de 1834, destinada ao preparo rudimentar de professores leigos com base no modelo europeu; porém, devido aos grandes problemas e atribulações instalados na educação, inúmeras reformas 
foram acontecendo na tentativa de reduzir a precariedade da formação dos educadores.

Para Moreira D’ Azevedo:

Era então deplorável o estado das escolas primárias em todas as capitanias do Brasil, poucas existiam e estas exercidas por homens ignorantes. Não havia sistema nem norma para a escolha de professores, e o subsídio literário não bastava para pagar o professorado. ( $D^{\prime}$ AZEVEDO, 1893 apud TANURI, 2000, p.62)

As reformas educacionais acerca da formação docente se intensificaram principalmente a partir do ano de 1.990, resultantes da indignação dos profissionais da educação perante o "baixo investimento, o aviltamento salarial dos professores, o enfoque tecnicista, a expansão desregrada dos cursos de licenciatura e a descaracterização da atividade docente". (ROMANOWSKI, 2010, p.82).

O movimento ganhou ainda mais força no Governo de Fernando Henrique Cardoso com o início da Reforma do Estado e a aprovação da Lei de Diretrizes e Bases da Educação Nacional LDB/1996 (Lei no 9.394/96), responsável por elevar a "formação do professor das séries iniciais ao nível superior, estabelecendo que ela seja realizada em universidades e em institutos superiores de educação, nas licenciaturas e em cursos normais superiores." (TANURI, 2000 p.61).

Em um cenário de extrema insatisfação e críticas sobre o locus da formação docente, surgiu no Brasil a formação continuada, com a finalidade de superar as lacunas deixadas pela formação inicial e resgatar a identidade do profissional da educação por meio de uma capacitação alternativa, destinada a contribuir com crescimento pessoal e profissional desses agentes do conhecimento (LIBÂNEO, 2004).

Nesse contexto apresentado, surge no Brasil, há quase duas décadas, a formação continuada de professores objetivando oferecer oportunidades de aprendizado e desenvolvimento, motivando-os a se reconhecerem como sujeitos responsáveis pelo "levantamento de questões sérias acerca do que ensinam, como devem ensinar, e quais são as metas mais amplas pelas quais estão lutando" (GIROUX, 1997, p.161).

Nesta perspectiva, é imprescindível que os profissionais de ensino busquem além dos conhecimentos e habilidades adquiridos na formação inicial, objetivar construir uma identidade profissional capaz de contribuir com sua dinâmica de trabalho, tornando-a menos mecânica e mais significativa no espaço que ocupam (TANURI, 2000).

A profissão do professor nos tempos atuais está marcada por intensificação de quantificação de tarefas 
e de maior complexidade é necessário que ele continue estudando e se qualificando para poder realizar melhor seu trabalho na sala de aula. A formação continuada deveria apoiar, criar e potencializar uma reflexão real dos sujeitos sobre sua prática docente nas instituições educacionais e em outras instituições, de modo que lhes permitisse examinar suas teorias implícitas, seus esquemas de funcionamento, suas atitudes, etc.., estabelecendo de forma firme um processo constante de auto avaliação do que se faz e por que se faz. (INBERNÓN, 2010, p. 47)

Muitos programas vêm sendo desenvolvidos buscando apoiar a capacitação continuada dos docentes oferecidos por órgãos públicos e privados, nos formatos de curso de extensão, pós-graduação lato sensu, cursos rápidos de aprimoramento, entre outros. Particularmente, destacamos as ações do governo federal para cursos de formação continuada, as quais têm sido viabilizadas através da educação a distância, sendo atualmente uma bandeira forte em todos os meios, seja por meio das universidades e faculdades privadas ou públicas. Nesse sentido, os governos estaduais vêm implementando ações de formação continuada através das secretarias estaduais de educação.

De acordo com estudos realizados por Gatti (2008, p. 58), é perceptível que muitas das iniciativas públicas de formação continuada no setor educacional adquiriram a "feição de programas compensatórios e não propriamente de atualização e aprofundamento em avanços do conhecimento", tendo como única finalidade suprir aspectos da má-formação anterior, o que acaba estabelecendo uma política paliativa. Essa forma de trabalho descontextualizada das reais necessidades do seu público alvo desmotiva e empobrece a participação dos envolvidos, estabelecendo formas de exclusão mascaradas por um discurso de inovação, tecnologização e modernização. Vale lembrar que o discurso atual em torno da inovação tem desgastado o ambiente acadêmico, tanto no que diz respeito ao seu pessoal quanto e principalmente em questões materiais, ocorrendo aplicação equívoca de recursos, desperdícios e falta de planejamento sério.

Inbernón (2009) concorda com Gatti (2008) afirmando que o propósito da continuidade da formação,

$$
\begin{aligned}
& \text { deveria ser ressituar o } \\
& \text { professorado para ser } \\
& \text { protagonista ativo de sua } \\
& \text { formação em seu contexto } \\
& \text { trabalhista, no qual deve } \\
& \text { combinar decisões entre o } \\
& \text { prescrito e o real, aumentar }
\end{aligned}
$$


seu autoconceito, sua consideração e seu status trabalhista e social. (INBERNÓN, 2009, p. 37).

Dentro da temática apresentada, identificamos que muito se tem questionado sobre a formação inicial de professores e a continuidade de seus aprendizados para seu aprimoramento profissional. Nesse sentido, conforme Freire, "ensinar inexiste sem aprender e vice-versa e foi aprendendo socialmente que, historicamente, mulheres e homens descobriram que era possível ensinar" (FREIRE, 1996, p.12). O autor faz uma reflexão sobre a importância do estudo incessante para a prática docente, que não deve ser extinta com aquisição do diploma de licenciatura ou com o ingresso no primeiro emprego. Portanto, após a citação destes autores, queremos destacar que existem diferentes concepções de formação continuada, havendo nessa modalidade de formação uma clara preocupação em preencher lacunas da formação inicial, com vistas ao desenvolvimento profissional e pessoal de professores, ensejando, assim, uma ação transformadora na prática pedagógica desses agentes.

De acordo com Demailly (1992 apud MOTA 2009), a autora apresenta uma classificação sobre a formação continuada em quatro modelos ou formas que são:

A universitária - que são os projetos de caráter formal, extensivo, vinculado a uma instituição formadora, promovendo titulação específica.

A escolar - consistindo em cursos com bases estruturadas e formas definidas pelos organizadores ou contratantes, programas, temas e normas de funcionamento que são definidas pelos que contratam e, geralmente, estão relacionados a problemas reais ou provocados pela incorporação de inovações. A contratual - negociação entre diferentes parceiros para o desenvolvimento de um determinado programa. É a forma mais comum de oferta de curso de formação continuada, sendo que a oferta pode partir de ambas as partes.

A interativa-reflexiva - as iniciativas de formação se fazem a partir da ajuda mútua entre os professores em situação de trabalhos mediados pelos formadores. (DEMAILLY, 1992 apud MOTA, 2009, p.209).

De acordo com a classificação de Demailly (1992), nosso curso de formação continuada "O Diálogo e a Problematização" se encaixa na forma interativa-reflexiva. 0 desafio para a formação continuada está em romper com modelos padronizados e em criar sistemas diferenciados que possam atender ao desenvolvimento profissional de 
acordo com suas necessidades específicas, concebendo-se a formação como um trabalho de reflexão crítica sobre as práticas e de reconstrução permanente de uma identificação pessoal e profissional, em interação mútua, superando processualmente as limitações locais e caprichos individuais a fim de alcançar o desejo de uma educação que seja efetivamente para todos e que valorize a igualdade na formação geral.

Diante desta perspectiva, apresentamos a seguir, a proposta de formação continuada que tem como base as ideias de Freire (2010). Consideramos que "educação é comunicação, é diálogo, na medida em que não é a transferência de saber, mas um encontro de sujeitos interlocutores que buscam a significação dos significados" (FREIRE, 2010, p.69) e se ela é

[...] esta relação entre
sujeitos cognoscentes,
mediatizados pelo objeto
cognoscível, na qual o
educador reconstrói,
permanentemente, seu ato
de conhecer, ela é
necessariamente, em
conseqüência, um que-fazer
problematizador. (FREIRE,
2010, p.81).

Freire reconhece a importância desse 'que-fazer' como que uma atuação vigorosa de cada educador no meio em que está inserido e que seus desejos, claramente refletidos e internalizados, transpareçam nesse meio, problematizando tanto o espaço e seu contexto como a si mesmo, conscientizando-se como sujeito, ator e membro desse mesmo espaço. É preciso descobrir que os problemas, limites e dificuldades vêm de vários lados, de várias realidades externas; no entanto, cada educador também tem o mesmo compromisso e deve descobrir-se ator do meio em que está inserido, sugerindo, propondo, provocando e promovendo mudanças, pensando e repensando constantemente a sua própria ação.

\section{RESULTADOS}

Motivados por Freire (1965) e pela crença de que "todos ensinam a todos" (RIOS, 2001, p.36), idealizamos em conjunto com diretores e supervisores de ensino da rede pública estadual de Marília, um curso de extensão baseado no diálogo e na problematização, acreditando que é imprescindível a "formação do profissional reflexivo, que pensa-na-ação, cuja atividade profissional se alia à atividade de pesquisa". (PEREIRA, 2007, p. 41)

Desse modo, foram privilegiadas as necessidades reais da escola como eixo condutor desse curso de extensão, confiantes de que os saberes compartilhados enriquecerão a prática de todos, sobre diferentes perspectivas (ROMANOWSKI, 2010). 
Com a participação das equipes escolares, o grupo de supervisores e gestores detectou seus maiores problemas, seus principais avanços e quais as propostas que agregariam qualidade às suas instituições escolares, a fim de promover novas possibilidades a partir de seu próprio contexto.

Desencadeadas as ações, definimos coletivamente os temas geradores para 0 processo de formação continuada em serviço que estaremos desenvolvendo a partir desse diagnóstico, ação que favorece a participação de todos os envolvidos.

Os temas priorizados foram: a gestão democrática, a gestão pedagógica, a função social da escola, os indicadores de desempenho, as avaliações em larga escala e a construção/implementação do Projeto Político-Pedagógico da escola, este sendo o documento fundamental para a orientação e realização das ações planejadas.

O projeto de formação continuada busca identificar e ampliar as possibilidades de qualificação da atuação da equipe gestora das escolas e dos participantes da universidade a partir de um espaço de formação que privilegiará a interlocução entre os conhecimentos teóricos e as ações das equipes de gestão implementadas no cotidiano das escolas, pela tematização das práticas e sua problematização.

\section{CONCLUSÃO}

Tendo como eixo orientador o conceito de dialogicidade problematizadora, buscamos oportunizar a todos os envolvidos a vivência no processo de construção de um curso de formação que não fosse previamente formatado por alguns, para que outros se submetessem a ele. A proposta explora a culminância das experiências trazidas do quotidiano escolar pelos educadores com o objetivo de fortalecer a autonomia na elaboração do conhecimento e na democratização das relações construídas.

Partimos do princípio de que trabalhar com profissionais da educação das escolas de educação básica é, sobretudo, uma troca constante de saberes, uma vez que professores, gestores e supervisores escolares são corriqueiramente defrontados pelos conflitos que envolvem a escola. Todo o projeto foi idealizado para que houvesse desenvolvimento mútuo, propiciando um "ensino com quem aprendo e vice-versa". Além da necessidade de interação, o aprender com o outro é um fator preponderante para quem trabalha com a formação de profissionais para atuarem na educação básica e que indispensavelmente, precisam conhecer esse nível de ensino de perto, para que a teoria não se distancie da prática, provocando as tão propaladas frases "a teoria é uma e a prática é outra" ou, a mais comum, "na prática, a teoria é outra". 
Concebemos, portanto, a concomitância de duas ações complementares: o diálogo e a problematização.

\section{REFERÊNCIAS}

FREIRE, Paulo. Pedagogia da autonomia: saberes necessários à prática educativa. São Paulo: Paz e Terra, 1996. (Coleção Leitura).

. Extensão ou comunicação. São. Rio de janeiro: Paz e Terra, 2010.

GATTI, B. A. Análise das políticas públicas para formação continuada no Brasil, na última década. Revista Brasileira de Educação, v. 13, n. 37, jan/abr.2008. http://dx.doi.org/10.1590/S1413-

24782008000100006

GIROUX, H. Os professores como intelectuais: rumo a uma nova pedagogia crítica da aprendizagem. Porto Alegre: Artes Médicas. 1997.

LIBÂNEO, J. C. Organização e gestão da escola: teoria e prática. 5 ed. rev. e ampl. Goiânia: Alternativa, 2004.

MACHADO, L. M. Considerações sobre a natureza do trabalho científico. In:

LABEGALINI, A. C. F. B.; MAIA, G. Z. A.; MACHADO, L. M. (Org.) Pesquisa em educação: passo a passo. Marília: Edições M3T Tecnologia e Educação, 2007.

MOTA, F. A. B. Formação continuada de professores: aspectos históricos e perspectivas contemporâneas. Atos de Pesquisa em Educação, v. 4, n. 2, p. 206-219, mai/ago. 2009.

NÓVOA, A. Profissão professor. 2. ed. Lisboa: Porto, 1995.

PEREIRA, J. E. D. Formação de professores: pesquisa, representação e poder. Belo Horizonte: Autêntica, 2007.
INBERNÓN, Francisco. Formação permanente do professorado: novas tendências. São Paulo: Cortez, 2009.

Formação continuada de professores. Lisboa; Porto Alegre: Artmed, 2010.

RIOS, T. A. Compreender e ensinar: por uma docência da melhor qualidade. 2. ed. São Paulo: Cortez, 2001.

ROMANOWSKI, J. P. Formação e profissionalização docente. 4. ed. Curitiba: Ibpex, 2010.

TANURI, L. M. História da formação de professores. Revista Brasileira de Educação, São Paulo, n. 14, p. 62, maio/ago. 2000.

Recebido para publicação em 12/08/2014

Revisado em 04/09/2014

Aceito em 11/09/2014 